\title{
Proposed Organizational Ethical Commitment Paradigm for the Use of ICTs in Business Organizations
}

\author{
Michelle M. Ramim \\ Nova Southeastern University, Ft. Lauderdale, FL, USA
}

ramim@nova.edu

\begin{abstract}
Technological advances and the increasing popularity of the Internet have contributed to the flourishing of information and communication technologies (ICT) in business organizations. Employees' unethical conduct has intensified due to the increase use of ICT. In this paper, an Organizational Ethical Commitment Paradigm is offered. At the basis of the proposed paradigm, the existence of code of conduct represents a fundamental establishment of organizational ethical commitment. At the middle layer of the proposed paradigm, a moderate organizational ethical commitment is established where the code of conduct not only created, but employees are aware of such code. At the paradigm's top level, the most meaningful organizational ethical commitment is apparent where employees are familiar with their organizational code of conduct. Implications to practice and research are contributed to the understanding of ethical decision making.
\end{abstract}

Keywords: ICTs, Code of Conduct, ethical decision making, Organizational Ethical Commitment.

\section{Introduction}

Business organizations have been undergoing a paradigm shift from traditional communication tools to Internet-enabled information and communication technologies (ICTs) (Cleveland, 2011; Saunders, 2002). Such advances have enabled business organizations to implement ICTs technologies in the day to day operation. Employees' dependency on ICTs for their daily operation has proliferated over the past two decades (Nurmilaakso, 2009). Moreover, numerous studies have demonstrated a significant impact of ICTs (i.e. Customer Relationship Management (CRM), electronic commerce, enterprise resource planning (ERP), supply-chain management, just to name a few) on productivity and annual financial performance of business organizations (Antlová, 2009; Laudon, \& Laudon, 2010; Saunders, 2002). Ethical issues with employees' misuse of ICTs have been raised by several scholars and were noted as a major concern (Coughlan, 2005; Kuo \& Hsu, 2001; Spence, 2009). Moreover, scholars argued that employees' unethical conduct

Material published as part of this publication, either on-line or in print, is copyrighted by the Informing Science Institute. Permission to make digital or paper copy of part or all of these works for personal or classroom use is granted without fee provided that the copies are not made or distributed for profit or commercial advantage AND that copies 1) bear this notice in full and 2) give the full citation on the first page. It is permissible to abstract these works so long as credit is given. To copy in all other cases or to republish or to post on a server or to redistribute to lists requires specific permission and payment of a fee. Contact Publisher@,InformingScience.org to request redistribution permission. has intensified due to the ubiquitous technology use at the work place (Cronan \& Al-Rafee, 2008; Pillsbury, 2004; Weatherbee, 2010). Numerous examples of wide range of ICTs misuse include employees using social networking website to retrieve personal information posted by users, posting their personal information in social networking websites during work hours (Fernandez, 
2009), engaging in software piracy during work hours (Cronan \& Al-Rafee, 2008), copying corporate proprietary information, sharing username and password data (Naude \& Hörne, 2006), and more. Such examples of ICTs misuse range in severity, and may go unnoticed by corporate managers (D'Arcy \& Hovav, 2007). Finally, ICTs misuses have resulted in substantial expenses to the organization ranging from corrective actions, loss of employees, low- moral, breach of corporate data, potential liabilities and legal risk, loss of customers, and reduced corporate image.

In an effort to address employees' unethical use of ICTs, business organizations have implemented a code of conduct. A code of conduct is a set of guidelines and policies that organizations create in order help govern its employees' decisions and actions. The use of code of conduct in U.S. organizations originated from the Foreign Corrupt Practices Act (FCPA) of 1977 (O'Dwyer $\&$ Madden, 2006). Moreover, the code of conduct serves to guide employees on resolving ethical dilemmas in their daily decisions with other employees, customers, and suppliers. The code also provides a reflection of organizations' mission, values, and standards for their stakeholders (Coughlan, 2005; O’Dwyer \& Madden).

In recent years, some organizations have extended their code of conduct to include particular guidelines that address the ethical use of ICTs, and specifically social networking tools in the workplace. Overall, a number of studies have reported that business organizations, which established a code of conduct to specifically address such issues, experienced slightly lower incidents of unethical behavior compared with those that have not established one (Yahr, Bryan, \& Schimmel, 2009). Such findings give rise to evolving the code of conduct document to promote effectiveness. As the code develops, relevant policies, and guidelines are added to reflect the ethical culture of the particular organization. However, it is evident that the mere existence of the code of conduct is not sufficient to reduce misuse of ICTs (Rawwas et al., 2004; Yahr, Bryan, \& Schimmel, 2009). Rather, comprehensive practices in business organizations enforced by middle and upper management, may contribute towards the reduction in unethical incidents and the establishment of an organizational ethical climate. It appears that a consistent organizational ethical commitment paradigm for ethical decisions is needed. Such paradigm will provide guidelines and directions for middle and upper management to help them guide their employees on ethical usage of ICTs and, specifically the use of social networking tools.

\section{Existence of Organizational Code of Conduct}

Business organizations appear to mention their code of conduct in their corporate documents such as annual reports, mission statements, and company's website (Geva, 2006; Wotruba et al.,2001).

Figure 1 illustrates Wotruba et al. (2001)'s framework by indicating the processes that a code of conduct development and implementation influence the organizational ethical climate.

In their model, Wotruba et al. (2001), attest that the code of conduct is created to serve three goals, namely, convey to the employees, customers, suppliers and other stakeholders the organization's attention to ethics, display the ethical values and principles, and guide the ethical behavior of its employees. Essentially, the code of conduct is a meaningful instrument that helps to set top management's expectations for ethical behavior by all employees in the organization. Other researchers emphasized the code of ethics as an instrument that can stimulate dialogue among employees about ethical dilemmas (Adams et al., 2001; Coughlan, 2005). However, the mere existence of a code of conduct does not guarantee that employees will engage in ethical use of ICTs, and that an organizational ethical climate has been established. 


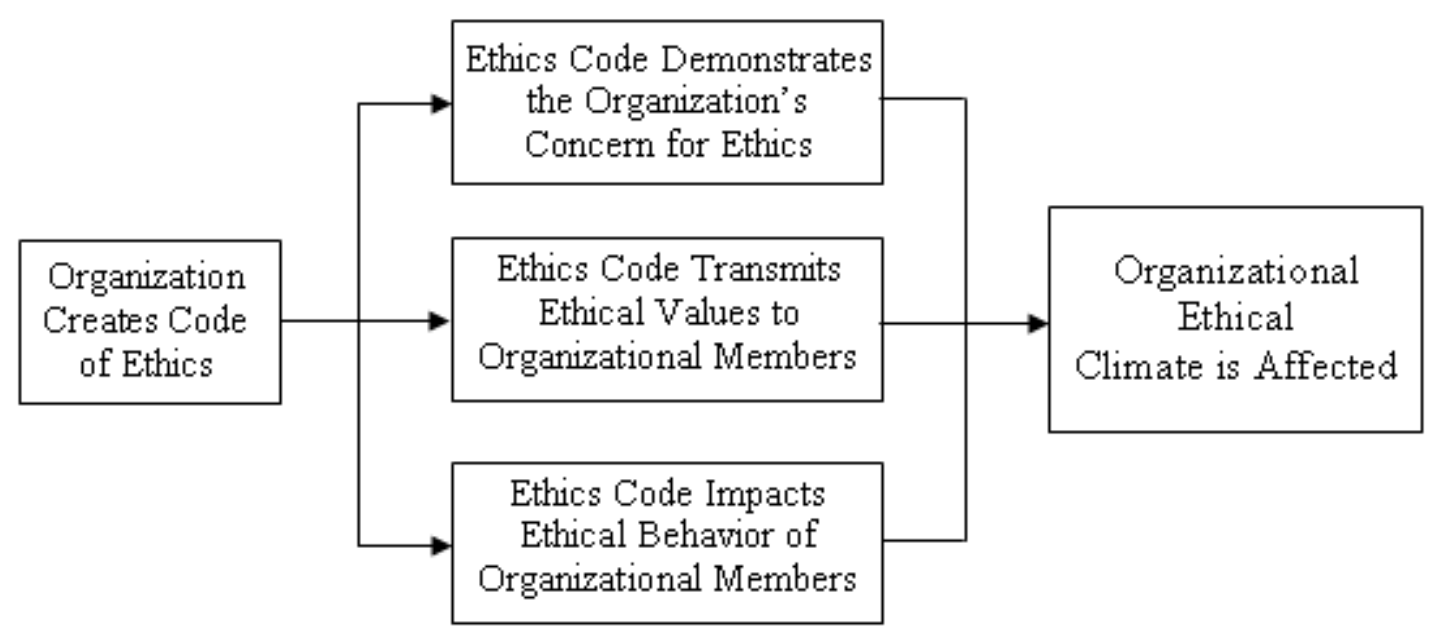

Figure 1. Framework for code of conduct processes (Wotruba et al., 2001)

\section{Awareness of the Code of Conduct}

Awareness of the code may vary among entry level employees and those tenured in the organization, and the combination of both may contribute towards the overall mixed ethical environment in the organization. Adams et al. (2001) reported a significance difference between top managers and supervisors among organizations where a code of conduct exist compared with ones where a code of conduct did not exist. Thus, top managers and supervisors appear to set the ethical expectations for others in the organizations. Though, Adams et al. (2001) found that employees could not recall the code specific content, the existence of the code signal to employees and top management the commitment that the organization requires of its employees. Interestingly, O'Dwyer and Madden (2006) found that most organizations provided their codes of conduct to new employees, but lacked formal procedures to support awareness programs of codes of conduct over time. O'Dwyer and Madden (2006) as well as Adams et al. (2001) pointed out the need to further study the implications of codes of conduct in business organizations particularly among entry level managers.

\section{Familiarity with Code of Conduct}

The presence of a code of conduct indicates that an organization is establishing its first-stage of commitment to guiding its employees about ethical decisions (Coughlan, 2005; O'Dwyer \& Madden, 2006). Employees' awareness of the code of conduct demonstrates an elevated level of commitment to ethics. In most organizations, new employees are introduced to the organization's code of conduct when first joining, though routine updates or training are scarce. Though, employees may not be able to recall the actual content of the code, they are still influenced to make ethical decisions (Wotruba et al., 2001). However, a deeper level of commitment organizational ethical climate is evident when employees are familiar with the code. Familiarity with the code is evident through employees and top managers reviewing and discussing the code of ethics regularly and as they are faced with ethical dilemmas. Some organizations provide annual ethics training, and may require their employees to pass ethics certification. For example, The National Institute of Health $(\mathrm{NIH})$ requires all its full-time employees to complete annual ethics training. Moreover, the NIH also requires its special volunteers, guest researchers, and temporary employees to complete similar annual ethics training. Full-time employees and senior managers can seek the advice and guidance of ethics counselors, and ethics attorneys. The NIH sees its commitment to ethics by conveying to its employees that they have the responsibility to learn the how the statutes and regulations are implemented in their organization (NIH, 2011). Aside from government 
agencies, other organizations such as the University of Illinois engages in annual ethics training, provides ethics guidance for decision makers, as well as publishes annual ethics guidebook and scenarios. A 2009 Employee Ethics Survey reported that when most employees were familiar with the code of conduct, more than two thirds of the employees reported managers and supervisors to include discussions about ethics in meetings (Illinois.gov, 2009).

Additional effort to imprint the code of conduct is evident through top managers and supervisors participation in the annual meetings aimed at updating the code, adding new policies, and adjusting guidelines. As part of such efforts, the code of conduct should also reflect sections referring to the ethical use of ICTs currently used in the organization.

A higher level of organizational ethical commitment, operationalized by employees' familiarity of the code of conduct, can contribute towards employees' perceptions of the usefulness of the code, which in turn, will have a direct positive impact on their ethical decisions when faced with daily dilemmas. Thus, a single step in the ethical direction (i.e. as noted in by the direction of the arrow in Figure 1) is not sufficient, rather highly desired effort by top managers to embed ongoing discussions about the code of conduct, demonstration of the relevancy of the code in ethical dilemmas, are the sequence of actions needed to establish familiarity.

\section{Proposed Organizational Ethical Commitment Paradigm}

Although, research has well documented sections of such paradigm, to date, it doesn't appear that a holistic paradigm for the overall stages of the organizational ethical commitment has been documented. Thus and following the literature about code of conduct, Figure 2 represents the proposed Organizational Ethical Commitment Paradigm.

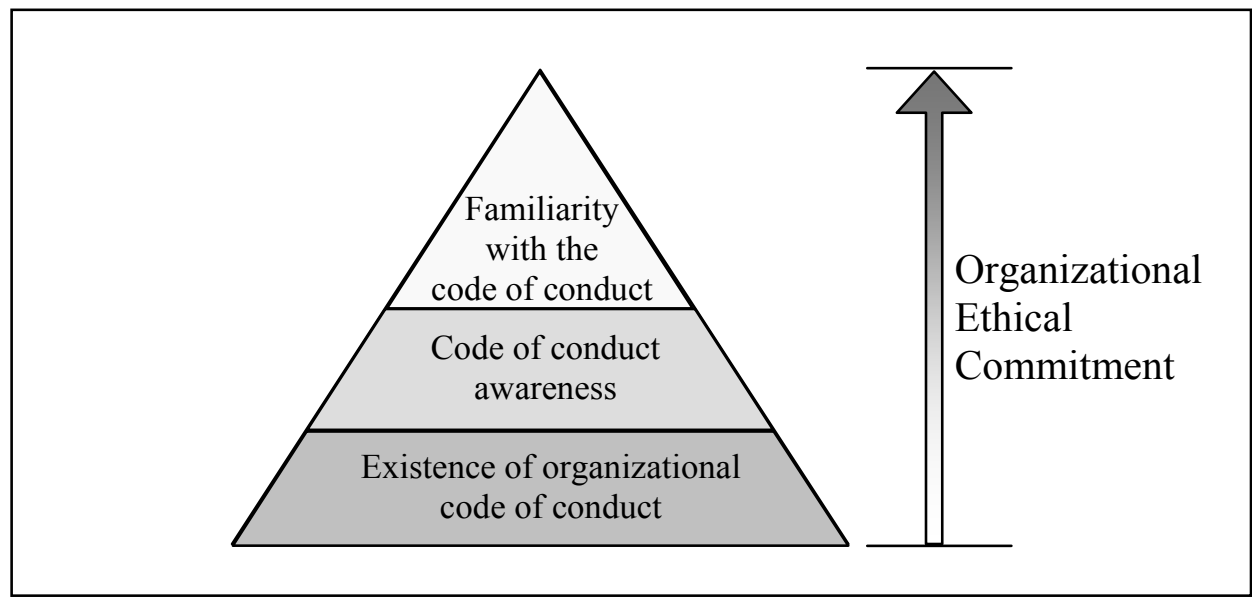

Figure 2. Organizational ethical commitment paradigm via code of conduct

At the base of the proposed paradigm, the existence of code of conduct represents a fundamental establishment of organizational ethical commitment (Coughlan, 2005; Oumlil \& Balloun, 2009). While such a code is merely created, and introduced to new employees, it may provide a limited contribution towards employees' ethical decision making. In those organizations, there is lack of support for awareness programs of the code of conduct (O'Dwyer \& Madden, 2006). A moderate organizational ethical commitment is established where the code of conduct not only created, but employees are aware of such code (O'Dwyer \& Madden, 2006). The top and the most meaningful organizational ethical commitment is apparent when employees are familiar with their organizational code of conduct. Also, at this top level of the proposed paradigm, the code of conduct is meshed into the organizational culture as well as daily corporate communications. At this top 
level, the organizational ethical commitment is a significant contributor to ethical decision making (Harris, 2002; Wotruba, Chonko, \& Loe, 2001) Familiarity has been defined as the understanding of a concept that is based on prior interactions, experiences, and learning (Gefen, 2000). Thus, familiarity with code of conduct suggests that employees understand the meaning of the code of conduct, the application and consequences of following the code. Researchers outline a number of approaches to developing familiarity including informing managers about issues and updates that the codes addresses, stimulating discussions, establishing understanding of scenarios where the codes applies, as well as understand the personal and organizational consequences of unethical behavior (Chonko, Wotruba, \& Loe, 2003; Wotruba et al., 2001). Thus, business organizations should move beyond building awareness, and into employee as well as organizational culture of familiarity with the code of conduct towards building an organizational ethical commitment. Top managers and supervisors play a critical role in setting the organizational ethical commitment. Beyond the establishment of artifact, the code of conduct should be discussed in board meetings. Establishing the highest level of organizational ethical commitment means an alignment of the code of conduct with corporate mission, corporate strategic documents, and demonstrating accountability. Merely appointing an ethics corporate director meets the lowest level of the organizational ethical commitment paradigm. On the other hand, involving the ethics corporate director in key strategic decisions, conducting accountability studies about employees understanding of the code, and reinventing the organizational ethical commitment meets the highest level of the organizational ethical commitment paradigm, the familiarity.

\section{Implications to Practice}

The implications of the proposed organizational ethical commitment paradigm to practice are twofold. First, Organizations should continue to strive to accomplish the highest level in the organizational ethical commitment paradigm. They should involve all employees in the process of establishing ethical commitment. Top managers and supervisors should continue to play key role in ensuring that employees are familiar with the code of conduct, engaged in regular ethical discussions, and corporate decisions should reflect the ethical commitment of the organization. Second, organizations can classify themselves at the level of ethical commitment paradigm that they are positioned. In cases that they fall below the top level of ethical commitment, measures should be taken to encourage employees to become familiar with the organizational code of conduct, and engage themselves in ethical decisions.

\section{Implications to Research}

The implications of the proposed organizational ethical commitment paradigm for research includes encouragement for further investigations of ethical decision making among employees, managers, and top executives. Future research should focus on using the paradigm in order to classify organizations across multiple industries or multiple companies within an industry, and benchmarking it against corporate profitability to assess if it pays to have the highest level of organizational ethical commitment.

\section{References}

Adams, J. S., Tashchian, A., \& Stone, T. H. (2001). Codes of ethics as signals for ethical behavior. Journal of Business Ethics, 29(3), 199-212.

Antlová, K. (2009). Motivation and barriers of ICT adoption in small and medium-sized enterprises. $E+M$ Ekonomie a Management, 2, 140-156.

Chonko, L. B., Wotruba, T. R., \& Loe, T. W. (2003). Ethics code familiarity and usefulness: Views on idealist and relativist managers. Journal of Business Ethics, 42(3), 237-252. 


\section{Ethical Commitment Paradigm}

Cleveland, A. (2011). Miles to go before we sleep: Education, technology, and the changing paradigms in health information. Journal of the Medical Library Association, 99(1), 61-69.

Coughlan, R. (2005). Codes, values, and justifications in the ethical decision-making process. Journal of Business Ethics, 59(1), 45-53.

Cronan, T. P., \& Al-Rafee, S. (2008) Factors that influence the intention to pirate software and media. Journal of Business Ethics, 78, 527-545.

D'Arcy, J., \& Hovav, A. (2007). Deterring internal information systems misuse. Communications of the $A C M, 50(10), 113-117$.

Fernandez, P. (2009). Online social networking sites and privacy: Revisiting ethical considerations for a new generation of technology. Library Philosophy and Practice, 1-10.

Gefen, D. (2000). E-commerce: The role of familiarity and trust. Omega, 28(6), 725-737.

Geva, A. (2006). A typology of moral problems in business: A framework for ethical management. Journal of Business Ethics, 69(2), 133-147.

Illinois.gov (2009). Employee ethics survey offices of the Illinois state. Retrieved April 2, 2011 from http://www2.illinois.gov/eec/Documents/AGCmpTrs-Emp_Ethics_Surv2009.pdf

Kuo, F. Y., \& Hsu, M. H. (2001). Development and validation of ethical computer self-efficacy measure: The case of shoplifting. Journal of Business Ethics, 32(4), 299- 315.

Laudon, K., \& Laudon, J. (2010). Essentials of MIS, 9/E. Upper-Saddle River: Prentice-Hall.

Naude, E., \& Hörne, T. (2006). Cheating or 'collaborative work': Does it pay? Issues in Informing Science and Information Technology, 3, 1-8.

Nurmilaakso, J. (2009). ICT solutions and labor productivity: Evidence from firm-level data. Electronic Commerce Research, 9(3), 173-181.

National Institute of Health (NIH). (2011). NIH ethics program overview. Retrieved April 2, 2011 from http://ethics.od.nih.gov/overview.htm

O'Dwyer, B., \& Madden, G. (2006). Ethical codes of conduct in Irish companies: A survey of code content and enforcement procedures. Journal of Business Ethics, 63, 217-236.

Oumlil, A. B., \& Balloun, J. L. (2009). Ethical decision-making differences between American and Moroccan managers. Journal of Business Ethics, 84, 457-478.

Pillsbury, C. (2004). Reflections on academic misconduct: An investigating officer's experiences and ethics supplements. Journal of American Academy of Business, 5(1/2), 446-454.

Rawwas, M. Y. A., Al-Khatib, J. A., \& Vitell, S. J. (2004). Academic dishonesty: A cross-cultural comparison of U.S. and Chinese marketing students. Journal of Marketing Education, 26(1), 89-100.

Saunders, G. (Ed.). (2002). The future of distance learning in the traditional university (Vol. 1). Hershey, PA: Idea Group.

Spence, E. H. (2009). A universal model for the normative evaluation of internet information. Ethics and Information Technology, 11(4), 243-253.

Yahr, M. A., Bryan, L. D., \& Schimmel, K. (2009). Perceptions of college and university codes of ethics. Journal of Academic and Business Ethics, 2(7), 1-10.

Weatherbee, T. G. (2010). Counterproductive use of technology at work: Information \& communications technologies and cyberdeviancy. Human Resource Management Review, 20, 35-44.

Wotruba, T. R., Chonko, L. B., \& Loe, T. W. (2001). The impact of ethics code familiarity on manager behavior. Journal of Business Ethics, 33(1), 59-69. 


\section{Biography}

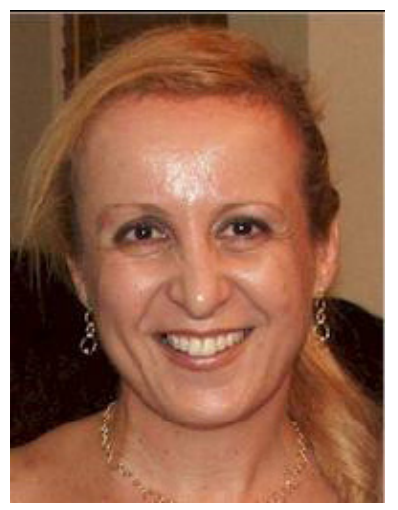

Dr. Michelle Ramim is a part-time professor at the Huizenga School of Business and Entrepreneurship at Nova Southeastern University. She has extensive experience in information technology (IT) consulting. Dr. Ramim directed the development and implementations of several IT projects including promotional and interactive websites for major enterprises such as Debeer (Diamond Trading Company). Her current research interests include ethical issues with IT, information security and crisis management, legal aspects of computing, as well as ethical decision making. She has published articles in peer-reviewed outlets including journals, conference proceedings, encyclopedias, and an invited chapter. Moreover, she has been serving as a referee research reviewer for national and international scientific journals, conference proceedings, as well as MIS textbooks. She earned her Bachelor's degree from Barry University in Miami Florida. Dr. Ramim has received her Executive MBA from Florida International University. She completed her Ph.D. in Information Systems at the Graduate School of Computer and Information Sciences, Nova Southeastern University in the area of ethical decision making. You can find her Website via: http://www.nova.edu/ ramim/ 